\title{
Follicular red dots: a normal trichoscopy feature in patients with pigmentary disorders?
}

Pontos vermelhos foliculares: um achado tricoscópico normal em pacientes com distúrbios da pigmentação?

\author{
Rodrigo Pirmez ${ }^{1}$ \\ Bárbara Cristina Rodrigues de Almeida ${ }^{3}$
}

\author{
Juan Piñeiro-Maceira² \\ Celso Tavares Sodré ${ }^{4}$
}

\begin{abstract}
Follicular red dots have been described as a trichoscopic feature of active discoid lupus erythematosus of the scalp and its presence associated with a better prognosis. We report five patients with pigmentary disorders in whom follicular red dots were detected during scalp examination. We suggest that this pattern is probably related to the rich vasculature that naturally envelops the normal hair follicle. The possible implications of such proposition in cases of discoid lupus erythematosus and other scalp disorders are also discussed.
\end{abstract}

Keywords: Albinism; Alopecia; Dermoscopy; Hair diseases; Lupus erythematosus, discoid; Vitiligo

Resumo: Pontos vermelhos foliculares foram descritos como achado tricoscópico de lupus eritematoso discóide do couro cabeludo em atividade e a presença destes associado a melhor prognóstico. Relatamos cinco pacientes com distúrbios da pigmentação nos quais pontos vermelhos foliculares foram detectados ao exame do couro cabeludo. Sugerimos que este padrão está provavelmente relacionado à rica vascularização que naturalmente envolve o folículo piloso normal. As possíveis implicações desta suposição nos casos de lupus eritematoso discóide e outras doenças do couro cabeludo também são discutidas.

Palavras-chave: Albinismo; Alopecia; Dermoscopia; Doenças do cabelo; Lupus eritematoso discóide; Vitiligo

\section{INTRODUCTION}

Trichoscopy is a new and evolving method and not all trichoscopic features are fully understood yet. We report five patients with pigmentary disorders in whom follicular red dots (FRD) were detected during scalp examination and discuss the significance of this finding.

\section{CASE REPORTS}

Five patients, 4 women and 1 man, age range 575 years old, consulting for pigmentary disorders were examined in our outpatient unit. Four did not present any hair or scalp disorders. One of the patients was being followed-up at our Hair Diseases Clinic for female pattern hair loss (FPHL). The patients had oth-

Received on 19.02.2013.

Approved by the Advisory Board and accepted for publication on 10.04.2013.

* Work carried out at the Sector of Dermatology, Teaching Hospital Clementino Fraga Filho - Universidade Federal do Rio de Janeiro (HUCFF - UFRJ) - Rio de Janeiro (RJ), Brazil.

Conflict of interest: None

Financial funding: None

1 MD - Dermatology Resident. Sector of Dermatology, Teaching Hospital Clementino Fraga Filho - Universidade Federal do Rio de Janeiro (HUCFF - UFRJ) Rio de Janeiro (RJ), Brazil.

MD, PhD - Dermatopathologist, Professor. Department of Pathology. Teaching Hospital Universitário Clementino Fraga Filho - Universidade Federal do Rio de Janeiro (HUCFF - UFRJ) - Rio de Janeiro (RJ), Brazil

MD - Pathology Resident. Department of Pathology. Teaching Hospital Clementino Fraga Filho - Universidade Federal do Rio de Janeiro (HUCFF - UFRJ) Rio de Janeiro (RJ), Brazil.

MD - Dermatologist, Professor. Sector of Dermatology, Teaching Hospital Clementino Fraga Filho - Universidade Federal do Rio de Janeiro (HUCFF - UFRJ) Rio de Janeiro (RJ), Brazil. 
erwise no notable medical history. Trichoscopy with polarized light was performed using a handheld dermoscope (DermLite II Hybrid M, 3Gen LLC, San Juan Capistrano, CA, USA). In the four patients without hair disorders (three with albinism and one with vitiligo), FRD were identified in a homogenous pattern of distribution throughout the scalp. In the fifth patient, who presented vitiligo and FPHL, FRD were irregularly distributed. In areas clearly affected by FPHL, FRD were present in a scattered fashion, with some being centered by hairs of various diameters, while others contained no hair shaft (Figure 1). We performed a dermoscopy guided 4-mm punch biopsy of her scalp, selecting a site where a FRD was present. Histopathology revealed hyperkeratosis with focal parakeratosis, marked basophilic degeneration of collagen and a sparse perivascular mononuclear cell infiltrate; features suggestive of chronic photodamage. No evident damage to the hair follicle was seen, and alterations suggestive of discoid lupus erythematosus (DLE) were not present (Figure 2).

\section{DISCUSSION}

FRD are erythematous structures regularly distributed around follicular ostia. Tosti et al. reported this pattern in five patients with active DLE and associated them to the presence of dilated vessels and red blood cell extravasation around the isthmus, associated with an atrophic epidermis. ${ }^{1}$

Since four of our patients had no history of hair loss and none had cicatricial alopecia, we believe that the red color is possibly related to the rich vasculature that naturally envelops the normal hair follicle. ${ }^{2}$ FRD in these cases were probably easily identified due to the lack of pigmentation of the overlying skin. Such proposition finds some support through the histopathological features seen in figure 2. Apart from signs of chronic actinic damage, biopsy of a FRD in the patient with FPHL revealed a non-involved hair follicle. Furthermore, we speculate that the irregular distribution pattern of FRD in this patient is a reflection of the disease process. Pattern hair loss is characterized by progressive miniaturization of hair follicles. Below each miniaturized follicle, there is a streamer of collapsed connective tissue sheath that once encircled the previously deep-rooted, terminal hair. After years, these streamers become less vascularized and, in advanced cases, replacement of follicles by connective tissue can be seen. ${ }^{3}$ The consequences of this miniaturization process are well characterized under trichoscopy by the observation of hair shaft thickness heterogeneity, as seen in this patient. ${ }^{4}$ Considering the sequence of events described, hairless areas where FRD were absent could be interpreted as representing the loss of follicles that may occur in long-standing disease.

If FRD indeed represent the vascular net that envelops the hair follicle, this could well serve as an explanation for the better prognosis in subjects with DLE presenting this pattern. ${ }^{1}$ One could suppose that FRD found in active DLE lesions characterize, in fact, viable follicles that could only be visualized owing to the presence of an overlying atrophic epidermis. These follicles, not yet fully affected by the inflammatory process, would therefore be responsible for better chances of hair regrowth.
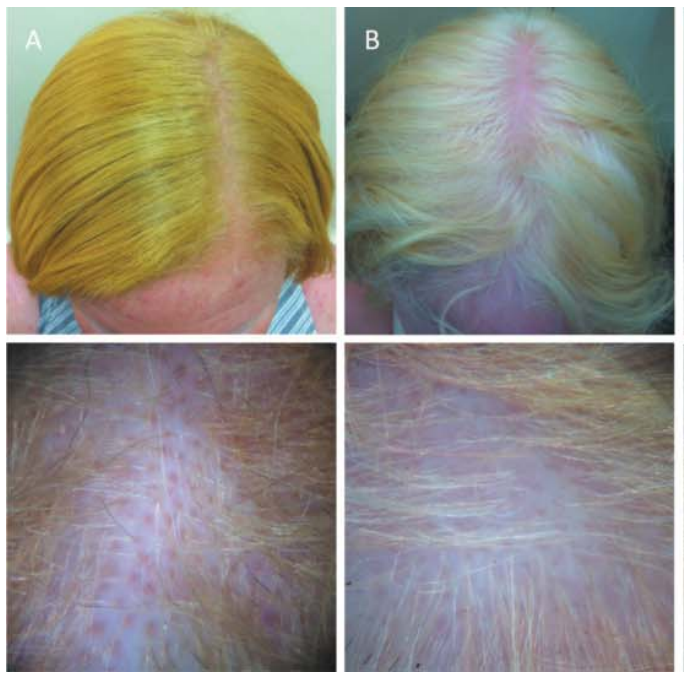
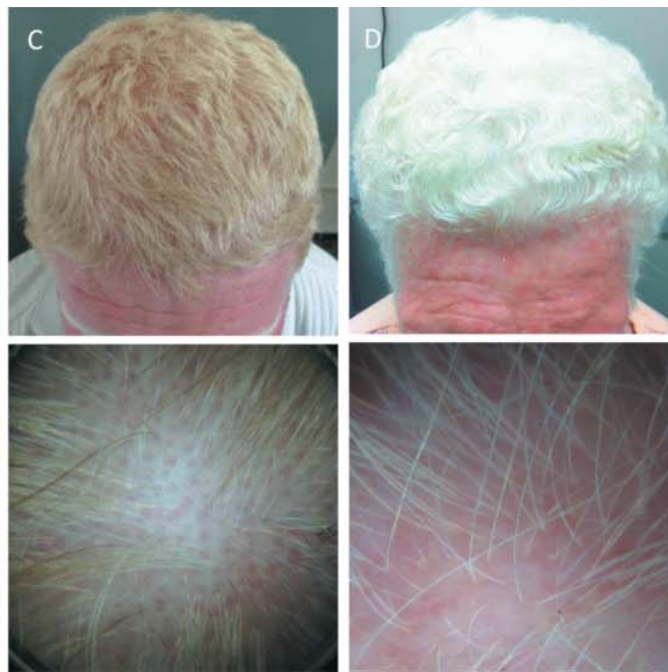

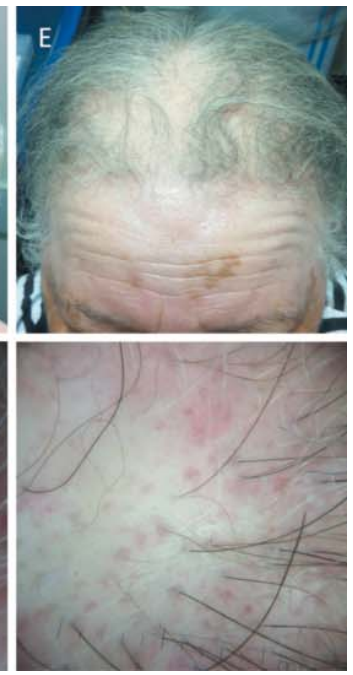

FigurE 1: Clinical presentation and respective trichoscopic images. A-C, patients with albinism. D-E, patients with extensive vitiligo. Note that patients A-D have no signs of hair disorder and present FRD in a homogeneous pattern of distribution. Patient E with evident FPHL and FRD present in a scattered fashion. (For all panels, original magnification x10) 


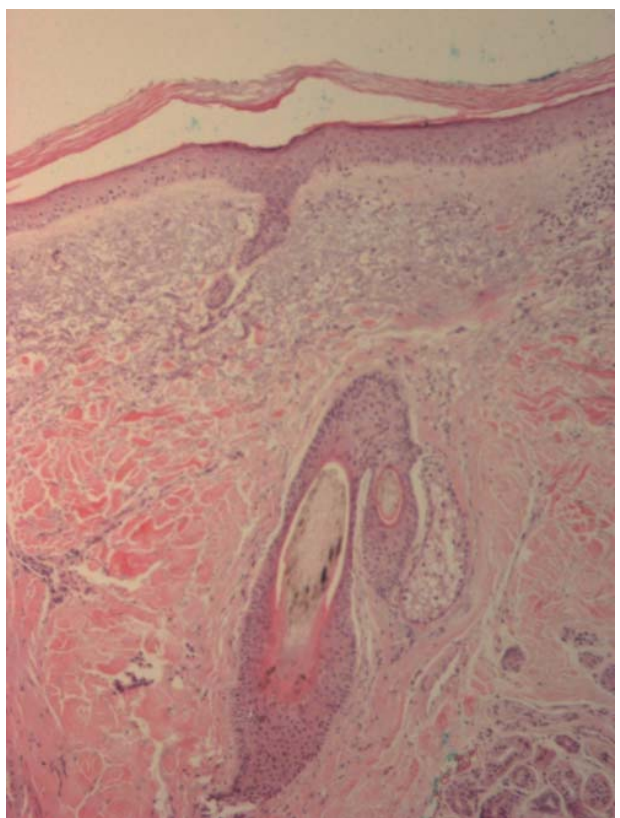

FIGURE 2: Biopsy specimen from the scalp of patient E showing hyperkeratosis with focal parakeratosis, marked basophilic degeneration of collagen and a sparse perivascular mononuclear cell infiltrate, features suggestive of chronic photodamage. No evident damage to the hair follicle was seen, nor were alterations suggestive of DLE. (H\&E, vertical section, $x 10$ )

\section{REFERENCES}

1. Tosti A, Torres F, Misciali C, Vincenzi C, Starace M, Miteva M, et al. Follicular red dots: a novel dermoscopic pattern observed in scalp discoid lupus erythematosus. Arch Dermatol. 2009;145:1406-9.

2. Paus R, Peker S, Sundberg JP. Biology of hair and nails. In: Bolognia JL, Jorizzo JL, Rapini RP, editors. Dermatology. 2nd ed. Philadelphia: Elsevier; 2008. p.965-86.

3. Sperling LC. Androgenetic alopecia. In: Sperling LC, editor. An atlas of hair pathology with clinical correlations. New York: The Parthenon Publishing Group; 2005. p.68-80.

4. Rudnicka L, Olszewska M, Rakowska A, Slowinska M. Trichoscopy update 2011. J Dermatol Case Rep. 2011;5:82-8.

5. Rakowska A, Slowinska M, Kowalska-Oledzka E, Warszawik 0, Czuwara J, Olszewska M, et al. Trichoscopy of cicatricial alopecia. J Drugs Dermatol. 2012;11:753-8

6. Macdonald A, Clark C, Holmes S. Frontal fibrosing alopecia: A review of 60 cases. J Am Acad Dermatol. 2012;67955-61.
FRD have also been reported in eyebrows of patients with frontal fibrosing alopecia (FFA). ${ }^{5} \mathrm{FFA}$ is a clinical variant of lichen planopilaris, a lymphocytemediated disorder that selectively involves hair follicles, leading to follicular destruction and cicatricial alopecia. It is characterized by progressive recession of the frontotemporal hairline; and eyebrow loss is frequently reported. Perifollicular erythema and scaling at the new frontal hairline are among clinical features. ${ }^{6}$ We believe FRD reported in these patients have a different pathological formation mechanism. Even though no histopathologic correlation was made, we presume that they correspond to perifollicular inflammation and are equivalent to the perifollicular erythema seen in the hairline of patients affected by FFA. ${ }^{5}$

In conclusion, we report five patients in whom the presence of FRD was proposed as a normal trichoscopic feature, appearing to be related to the rich vasculature that naturally envelops the normal hair follicle. Furthermore, the loss of this pattern in such patients may be a sign of hair follicle damage with poor prognosis. This is a small case series and further studies are necessary. Even though our subjects might not represent the everyday patient, we hope to offer grounds that might help to explain the nature and meaning of FRD helping the clinician to better interpret such finding when facing patients with other scalp disorders.

\author{
MAILING ADDRESS: \\ Rodrigo Pirmez \\ Rua Professor Rodolpho Paulo Rocco, 255. $5^{\circ}$ andar \\ Secretaria de Dermatologia \\ 21941-913 - Rio de Janeiro - RJ \\ Brazil \\ E-mail: rodrigopirmez@gmail.com
}

How to cite this article: Pirmez R, Piñeiro-Maceira J, Almeida BCR, Sodré CT. Follicular red dots: a normal trichoscopy feature in patients with pigmentary disorders? An Bras Dermatol. 2013;88(3):459-61. 